\title{
Morphological Analysis of Human Induced Pluripotent Stem Cells During Induced Differentiation and Reverse Programming
}

\author{
Anne-Marie Courtot, ${ }^{1,2}$ Aurélie Magniez, ${ }^{1}$ Noufissa Oudrhiri, ${ }^{1,3}$ Olivier Féraud,, Josette Bacci, ${ }^{4}$ \\ Emilie Gobbo, Stéphanie Proust, ${ }^{5}$ Ali G. Turhan, ${ }^{1,2,6}$ and Annelise Bennaceur-Griscelli, ${ }^{1,2,3}$
}

\begin{abstract}
The fine analysis of cell components during the generation of pluripotent cells and their comparison to bone fide human embryonic stem cells (hESCs) are valuable tools to understand their biological behavior. In this report, human mesenchymal cells (hMSCs) generated from the human ES cell line H9, were reprogrammed back to induced pluripotent state using Oct-4, Sox2, Nanog, and Lin 28 transgenes. Human induced pluripotent stem cells (hIPSCs) were analyzed using electron microscopy and compared with regard to the original hESCs and the hMSCs from which they were derived. This analysis shows that hIPSCs and the original hESCs are morphologically undistinguishable but differ from the hMSCs with respect to the presence of several morphological features of undifferentiated cells at both the cytoplasmic (ribosomes, lipid droplets, glycogen, scarce reticulum) and nuclear levels (features of nuclear plasticity, presence of euchromatin, reticulated nucleoli). We show that hIPSC colonies generated this way presented epithelial aspects with specialized junctions highlighting morphological criteria of the mesenchymal-epithelial transition in cells engaged in a successful reprogramming process. Electron microscopic analysis revealed also specific morphological aspects of partially reprogrammed cells. These results highlight the valuable use of electron microscopy for a better knowledge of the morphological aspects of IPSC and cellular reprogramming.
\end{abstract}

Key words: ducts; euchromatin; glycogen; hESC; hIPSC; hMSC; lipid droplets; macroautophagy; Matrigel; MEF; mesenchymal-to-epithelial transition; nucleoli; specialized junction

\section{Introduction}

NDUCED PLURIPOTENT STEM CELLS (IPSCS) are obtained by reprogramming adult or fetal differentiated somatic cells by the overexpression of four genes involved in pluripotency and cell proliferation. ${ }^{1}$ These results were first described in mice then in humans. ${ }^{2,3}$ The therapeutic potential of this technology in research and medicine is obvious. Fundamental questions arise, however, concerning the incomplete or complete reprogramming process because different degrees of induced pluripotency have been reported depending on the criteria used to assess the successful reprogramming. ${ }^{4}$

The pluripotency characteristics of human hIPSCs are currently evaluated by pluripotency-associated cell surface markers according to molecular criteria and functional aspect by teratoma assays. However, an analysis of the fine structure of the hIPSCs in comparison with human embryonic stem cells (hESCs) and differentiated cells exhibiting the same background could be a valuable tool to evaluate the cellular evolution from a differentiated to undifferentiated state. To this end, we have analyzed by electron microscopy the structure of pluripotent stem cells and mesenchymal cells generated from hESCs, which were then reprogrammed back to hIPSCs.

Few reports have analyzed the ultrastructural characteristics in mouse and human IPSCs, ${ }^{5,6}$ whereas hESCs have been extensively analyzed. ${ }^{7,8}$

We describe the detailed ultrastructural modifications occurring during induced reprogramming of embryonic mesenchymal cells into fully pluripotency, in the presence or in the

\footnotetext{
${ }^{1}$ Inserm U935, ES-TEAM Paris Sud, Ingestem, Villejuif, France.

${ }^{2}$ Université Paris Sud, Faculté de Médecine, Le Kremlin Bicêtre, France.

${ }^{3}$ Service d'Hématologie Biologique APHP, Hôpital Paul Brousse, GHU Paris Sud Villejuif, France.

${ }^{4}$ Service de Neurologie, ${ }^{5}$ Service de Virologie, Hôpital Bicêtre APHP, Le Kremlin Bicêtre, France.

${ }^{6}$ Service d'Hématologie Biologique APHP, Hôpital Bicêtre, GHU Paris Sud, Le Kremlin Bicêtre, France.
} 
absence of stromal cell feeder. These observations are compared with those obtained in partially reprogrammed cells.

\section{Materials and Methods}

\section{Human embryonic stem cells}

The hESC line H9 was imported from WiCell Research Institute (Madison, WI), after approval of the French Biomedicine Agency (Authorization to ABG, 2012).

\section{Generation of ESC-derived mesenchymal stem cells}

H9 hESCs were differentiated into mesenchymal stem cells (MSCs) by using our previously reported protocol. ${ }^{9}$ Briefly, H9 hESCs were deprived of murine embryonic fibroblasts (MEFs) and cultured in Dulbecco's modified Eagle's medium (DMEM)/F12 (Invitrogen) medium supplemented with $20 \%$ heat-inactivated fetal bovine serum (Hyclone), $1 \mathrm{ng} / \mathrm{mL}$ basic fibroblast growth factor (bFGF), $0.1 \mathrm{mM}$ nonessential amino acids, $1 \mathrm{mM}$ L-glutamine, $0.1 \mathrm{mM} \beta$-mercaptoethanol, and $0.1 \mathrm{mM}$ antibiotics (all from Invitrogen).

After 2 weeks, when the cells were $80 \%$ confluent, they were harvested by treatment with $0.05 \%$ trypsin/EDTA (Gibco) and amplified. Between passages 2 and 3, the cells exhibited a homogeneous morphology, and phenotypic analysis using fluorescent activated cell sorting showed positivity for CD90, CD105, CD146, CD166, CD44, and CD73 antigens and negativity for CD45, CD14, and CD3 antigens. To determine the mesenchymal nature of the cells, adherent cells were characterized for their multipotency using the Functional Identification Kit (R\&D Systems) and their ability to differentiate into adipocytes, chondrocytes, and osteoblasts. Lineages were tested by immunohistochemistry using polyclonal goat anti-mouse FABP4, monoclonal goat antihuman aggrecan, and mouse anti-human osteocalcin antibodies, respectively. Cell lines positive for mesenchymal differentiation markers were subsequently termed H9 MSCs.

\section{Reprogramming of H9 MSCs into H9 IPSCs}

Mesenchymal cells obtained from H9 hESCs were reprogrammed into hIPSCs using lentivirally induced Oct3/4, Sox2, Nanog, and Lin28 transgenes, following the described proto$\mathrm{col}^{3}$ After 20 days, colonies with hESC morphology were picked individually and hIPSC colonies were amplified on
MEF stromal layers. H9 hIPSCs shared the phenotypic characteristics of pluripotent hESCs, characterized by the surface expression of SSEA-3, SSEA-4, Tra-1-60, Tra-1-81, and SSEA-1 (ES Cell Characterization Kit, Millipore). Pluripotency of hIPSCs and hESCs was assessed in vivo by formation of teratoma into 6-week-old NOD-SCID mice (Charles River Laboratories) after intramuscular injection of $0.4 \times 10^{6}$, $1 \times 10^{6}$, and $3 \times 10^{6}$ hIPSCs and hESCs, with $5 \times 10^{6} \mathrm{MSCs}$ as a negative control. After 5-10 weeks, teratomas were dissected and fixed in $4 \%$ paraformaldehyde. Samples were embedded in paraffin and processed with hematoxylin and eosin staining and immunohistochemistry to assess the presence of ectodermal, endodermal, and mesodermal tissues.

Partially and fully reprogrammed IPSCs were obtained from human amniotic fluid cells reprogrammed by retroviral transgenes. Partially IPSCs were defined by the lack of transgene repression after the programming process as previously described. ${ }^{25}$ Partially (F50 line) and fully reprogrammed (PB39) colonies were also obtained by reprogramming human adult fibroblasts with virus of Sendaï (CytoTune, Life Technologies) according to the manufacturer's instructions. For reprogramming and subsequent cultures, colonies were cultured on hESC-qualified Matrigel-coated plates in NutriStem medium (Miltenyi Biotec).

\section{Pluripotent stem cell culture conditions}

hESC line H9 and hIPSCs were maintained on MEFs, mitotically inactivated by mitomycin C (Sigma Aldrich), and DMEM/F-12 medium supplemented with $20 \%$ Knockout serum replacer, $0.1 \mathrm{mM}$ nonessential amino acids, $1 \mathrm{mM} \mathrm{L}$ glutamine, $0.1 \mathrm{mM} \beta$ mercaptoethanol, $1 \times$ penicillin-streptomycin, and $10 \mathrm{ng} / \mathrm{mL}$ human recombinant bFGF (all from Invitrogen). After 7 days of culture, cells were manually plucked for glutaraldehyde fixation.

For feeder-free experiments, pluripotent stem cells were cultured on hESC-qualified Matrigel-coated plates (BD Biosciences) in mTeSR1 medium (Stem Cell Technologies) according to manufacturer's guidelines. Colonies were manually harvested as for feeder dependent cultures.

\section{Preparation of supernatant particles from cultures}

hESC- and hIPSC-conditioned medium were collected every day for 7 days and pooled for particle isolation. To

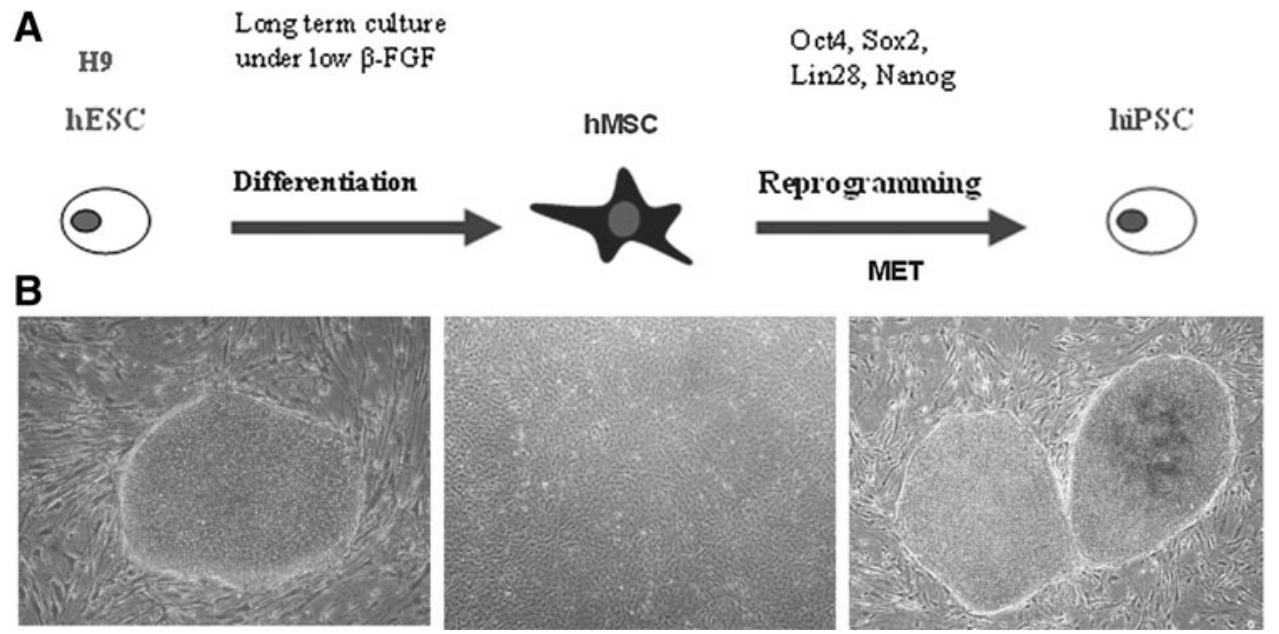

FIG. 1. Schematic protocol and cell lines. (A) Experimental protocol used for the optical and electronic analysis: H9 hESCs were differentiated into H9 MCSs and then reprogrammed into $\mathrm{H} 9$ hIPSCs. (B) Optical morphology of H9 hESCs, H9 hMSCs, and H9 hIPSCs, respectively. hESC, human embryonic stem cell; MSC, mesenchymal stem cell; hIPSC, human induced pluripotent stem cell. 
remove large cell debris, the supernatants were centrifuged at $1500 \times g$ for $15 \mathrm{~min}$ at $4^{\circ} \mathrm{C}$. The supernatants were then collected and centrifuged at $13,000 \times g$ for $2 \mathrm{~min}$ at $4^{\circ} \mathrm{C}$. The supernatants were collected again and centrifuged a last time at $15,000 \times g$ for $45 \mathrm{~min}$ at $4^{\circ} \mathrm{C}$. The pellets were then prepared for transmission electron microscopy (TEM).

\section{Transmission electron microscopy}

During culture, hESCs, hIPSCs, hMSCs, and MEFs were either manually plucked or scraped, gently centrifuged, and pelleted before the TEM process as follows.

The cells were fixed in $2.5 \%$ glutaraldehyde in phosphatebuffered saline (PBS) for $1 \mathrm{~h}$ at $4^{\circ} \mathrm{C}$, washed in PBS, and fixed in $1 \%$ osmium tetroxide in PBS for $1 \mathrm{~h}$. They were dehydrated in ascending series of graded ethyl alcohols, then in propylene oxide. Each sample was infiltrated with the resin before being embedded in epoxy resin and polymerized.

Semi-thin sections of about 0.5 to $1 \mu \mathrm{m}$ were obtained and colored with Toluidine blue before being examined via a light microscope with an associated digital camera, hooked to a computer for image processing and editing (Tribun System). Thin sections of about $70 \mathrm{~nm}$ were contrasted with heavy metals (uranyl acetate and lead citrate) and were examined using a Hitachi transmission electron microscope at an accelerated voltage of $80 \mathrm{kV}$. Images were photographed on film. Negative scanner produced digital images, edited by Adobe Photoshop and Microsoft Power Point.

\section{Results}

Figure 1 shows the experimental protocol used for the optical and electron microscope analysis of $\mathrm{H} 9 \mathrm{hMSCs}, \mathrm{H} 9$ hESCs, and H9 hIPSCs.

\section{Structural analysis of $\mathrm{H} 9$ hMSCs}

As expected, human H9-derived MSCs appeared as fusiform cells with digital expansions. The cells appeared either isolated or overlapping each other, generating confluent colonies (Fig. $2 \mathrm{~A}$ and $2 \mathrm{~B}$ ). At the ultrastructural level, in the nucleus, chromatin is represented as patches of heterochromatin inside the nucleoplasm, associated with the nucleolus, or localized at the inner border side of the nuclear envelope (Fig. 2C). The cytoplasm appeared polarized because the side of the cell in contact with the dish contained a thick layer of dense filaments corresponding probably to actin filaments as previously described (Fig. 2B).

Interestingly, cytoplasm was filled with well-formed dilated cisternae of a rough endoplasmic reticulum and contained dense material (Fig. 2C). However, the Golgi apparatus was sparse, and lipid droplets were rarely found. Similarly, phagosomes were rarely observed (Fig. 2C).

\section{Structural analysis of H9 hIPSCs and H9 hESCs cultured on MEF feeder cells}

H9 hIPSCs derived from H9 hMSCs were gathered as discoid colonies among mouse fibroblast feeder cells. Each hIPSC colony accumulated several distinct layers, the number of which could vary between colonies and even within different regions of the same colony (Fig. 3, A1). Colonies were organized from two to eight layers and were often flattened in their periphery. Overall detailed analysis revealed a
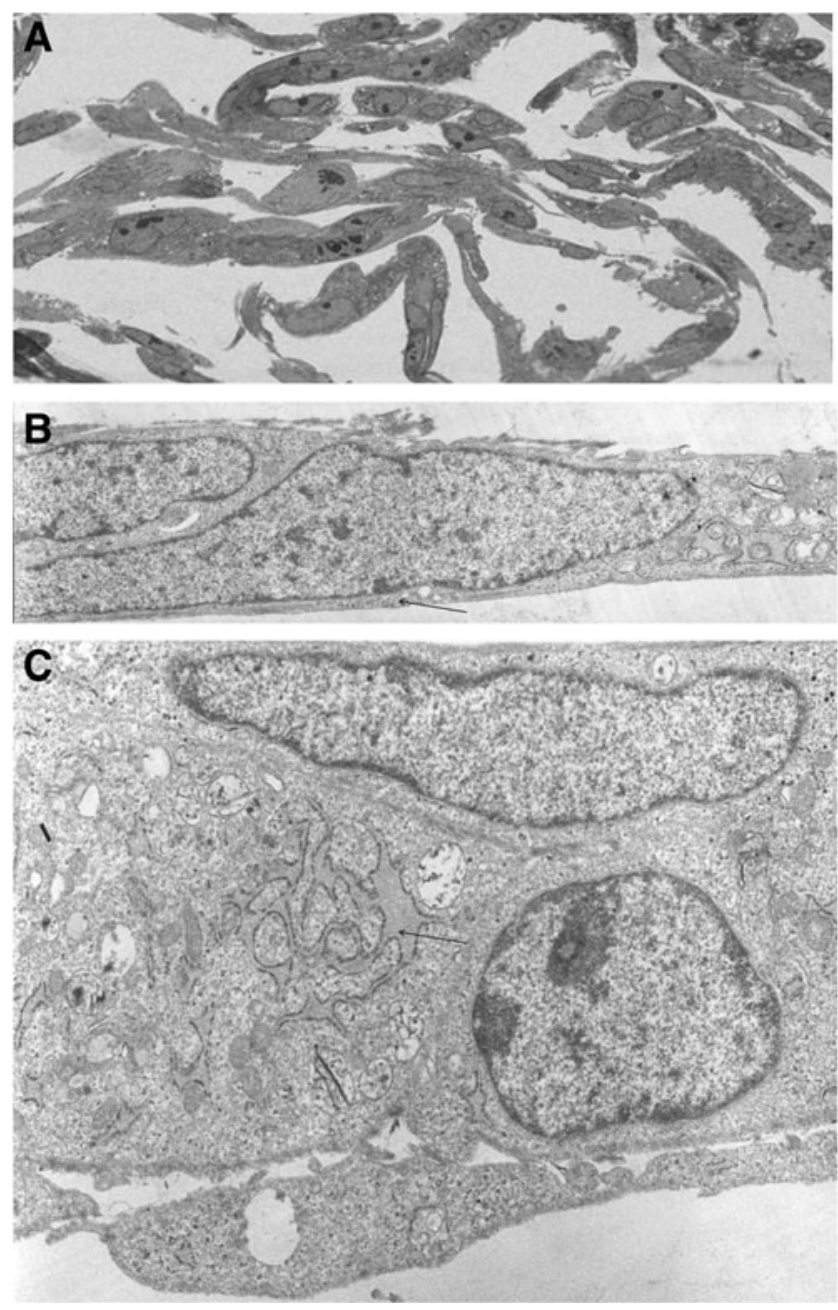

FIG. 2. Analysis of human (h)MSC. (A) Semi-thin sections of MSC. The fusiform cells with digital expansions are isolated or partially overlapped with each other in these confluent colonies. Optical microscopy, original magnification $\times 400$. (B) The cytoplasm is polarized because the side of the cell in contact with the dish contains a thick layer of dense filaments (arrow) running under the cell membrane. Transmission electron microscopy (TEM), original magnification $\times 5000$. (C) The cytoplasm is filled with well-formed dilated cisternae of a rough endoplasmic reticulum (arrow) and contains dense material. No phagosomes are seen inside the cells. In the nucleus the chromatin is represented as patches of heterochromatin inside the nucleoplasm, associated to the nucleolus, or localized at the inner border side of the nuclear envelope. TEM, original magnification $\times 10,000$.

high nucleo-cytoplasmic ratio as well as a well-defined nucleoli with a variable number, from one to four per cell, in all cells (Fig. 3, A2-A4). The cells without well-identified nucleolus were either in division (Fig. 3, A6) or in necrotic and apoptotic stages.

Importantly, the cells in contact with culture medium (upper side of the colony) presented several microvilli at their apical region with vacuoles of pinocytosis beneath them (Fig. 3B and 3C). The cells were in close connection with each other due to the presence of junction complexes at their upper lateral side. Among them, zonula adherens 

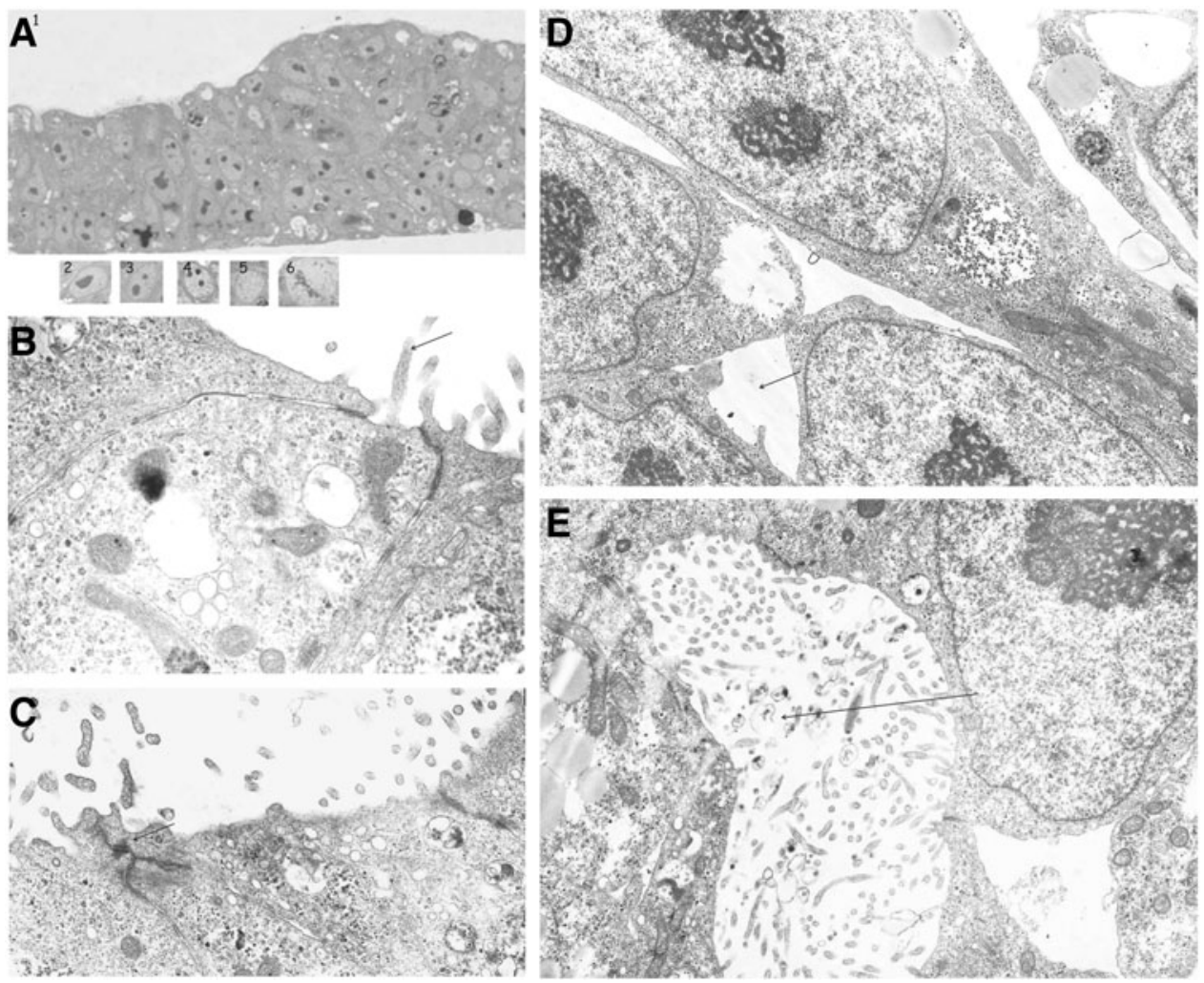

FIG. 3. Morphological architecture of H9 hIPSCs cultured on murine embryonic fibroblasts (MEFs). (A) Semi-thin section of H9 hIPSCs. This panel illustrates the general architecture of a colony The IPSCs are organized in colonies with microvilli at the upper side (A1). These cells have a high nucleo-cytoplasmic ratio and present a variable number of nucleoli (A2, A3, A4, A5). Some cells are in mitosis (A6). Optical microscopy, original magnification $\times 400$. (B) The cells at the upper side of the colony present several microvilli of nonintestinal type (arrow). TEM, original magnification $\times 15,000$. (C) The cells are closely related according to the presence of zonula adherens and macula adherens (arrow) with their intermediate filaments on each cytoplasmic side of the membranes. TEM, original magnification $\times 15,000$. (D) The cells inside the colonies had a high nucleo-cytoplasmic ratio and very significant intercellular spaces $($ arrow $)$. TEM, original magnification $\times 5000$. $(\mathbf{E})$ Presence of ducts inside the colony (arrow). These ducts are formed by apical differentiation of several epithelial cells. Inside these ducts are fractions of cell elements. TEM, original magnification $\times 6000$.

and macula adherens with their intermediate filaments on each cytoplasmic side of the membranes could be observed (Fig. 3B and 3C). In contrast, cells inside a colony had larger intercellular spaces (Fig. 3D). The cell membrane at the basal side of the colony (in contact with the culture dish) did not present any characteristics of differentiation. However, some of them possessed dense material running along the inner side of the membrane (data not shown).

We observed well-structured ducts, inside the colony, running from one layer to another (Fig. 3E). These ducts were formed by apical differentiation (including microvilli) of several epithelial cells, generating a connecting canalicular system between the colony and the culture medium. Small vesicles were present inside the ducts. These vesicles were probably secreted by the surrounding cells of the ducts.

The plasticity of the nucleus was suggested by its frequent deformations in relation with cytoplasmic elements, such as lipid droplets in its vicinity (Fig. 4A).

One important characteristic of the nuclei was the absence of heterochromatin clusters (Fig. 4A), contrasting with their parental hMSC nuclei (Fig. 2C). Indeed chromatin of all IPSCs possessed features of euchromatin (Figs. 3D and 4A).
Analysis of nuclear envelope revealed a constitution with classical features (Fig. 4B), but a layer could be observed inside the inner nuclear membrane that was thinner than those observed in differentiated cells, H9 hMSCs (Fig. 2C), or MEFs.

Nucleoli presented well-defined reticulated structures (Fig. 4A) with fibrillar centers corresponding to DNA and granular and fibrillar regions corresponding to rRNA precursors (Fig. 4B and 4C). The nucleolus appeared to be very large with a clear opening toward the nucleoplasm (Fig. 4D).

The cytoplasm contained free ribosomes, polyribosomes, and scarce portions of granular reticulum. The Golgi apparatus was more or less developed (Fig. 5A). Interestingly we observed a very high number of mitochondria, the size of which was highly increased, suggesting a potential fusion between them. In nearly all the sections observed, lipid droplets were found to be present and were often clustered in twos or threes and associated with glycogen rosettes (Fig. 5B).

Beside these cells, we observed cells presenting voluminous autophagic vacuoles in their cytoplasm (Fig. 6) and containing fused lipid droplets enclosed in a dense material.

The supernatants of different hIPSC culture dishes were collected to analyze the component of cell media by electron 

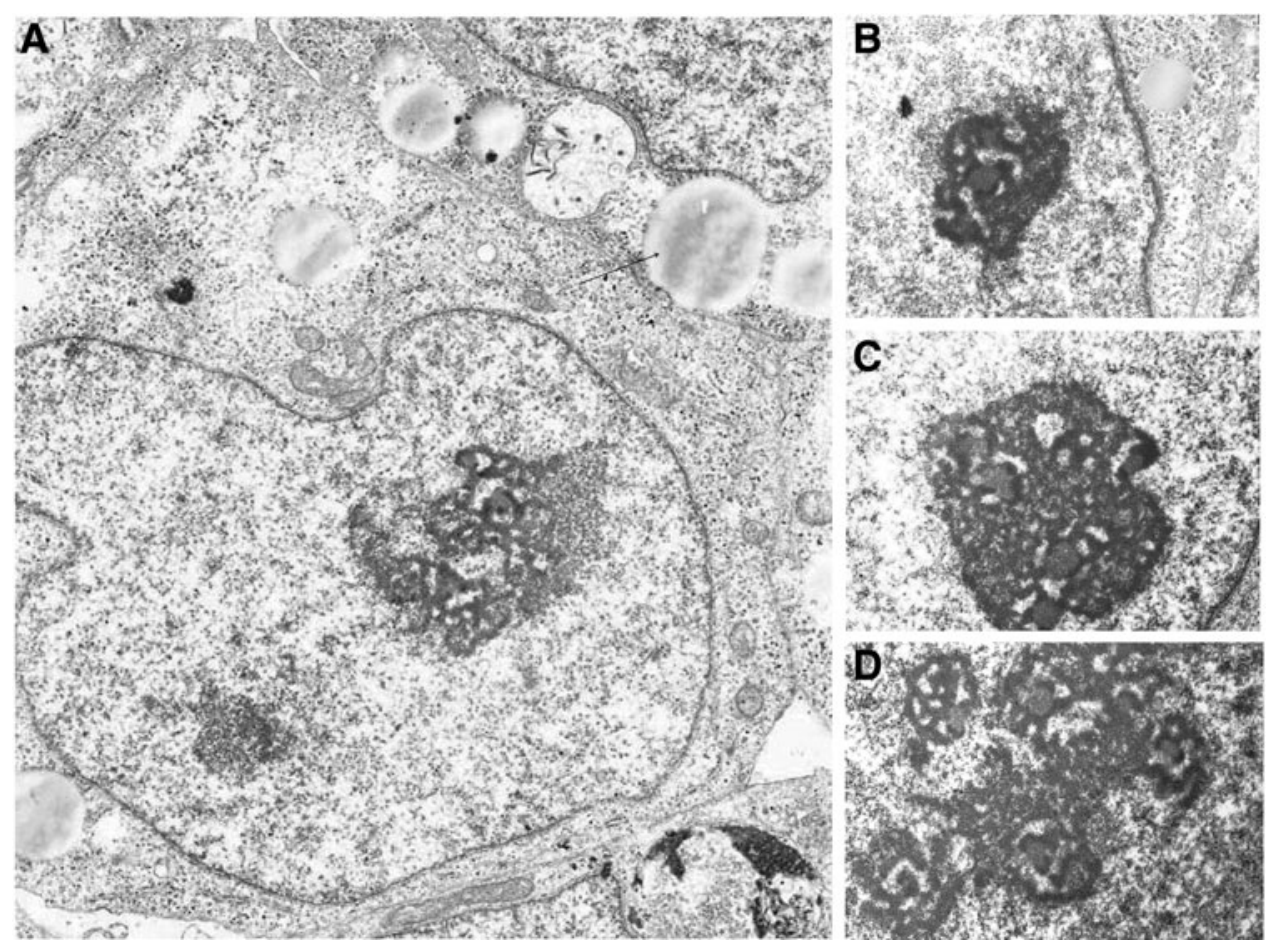

FIG. 4. Ultrastructural analysis of nucleus of H9 hIPSCs cultured on MEFs. (A) In the nucleus, the chromatin is of euchromatic type. The nucleolus is voluminous and has a well-defined reticulated structure. A thin layer can be observed inside the inner nuclear membrane. Plasticity of the nucleus is demonstrated by its frequent deformation in relation with cytoplasmic organelles. The cytoplasm contains ribosomes, lipid droplets, and glycogen (arrow). Sarcoplasmic reticulum is very scarce while mitochondria are present. TEM, original magnification $\times 5000$. (B, C, D) The nuclear envelope has a classical constitution (two membranes and nuclear pores). These three photographs, taken at the same magnification, show the different sizes of the nucleoli. In (D), the structure is open towards the nucleoplasm. TEM, original magnification $\times 15,000$.

microscopy. Beside structures arising from cytoplasm and nucleoplasm membranes, we identified virus-like particles, characterized by their clustering and a size of approximately $100 \mathrm{~nm}$. These particles were similar to mature and immature enveloped retroviral particles of the Retroviridae family,
Orthoviridae subfamily and could correspond to murine leukemia virus $(\mathrm{MuLV})$.

To confirm the murine origin of these viral particles and to evaluate the percentage of MEF cells bearing viral particles, we performed an ultrastructural analysis of mitomycin-treated
FIG. 5. Ultrastructural analysis of cytoplasm of $\mathrm{H} 9$ hIPSCs cultured on MEFs. (A) The cytoplasm contains free ribosomes, polyribosomes, and Golgi apparatus (arrow). TEM, original magnification $\times 15,000$. (B) Mitochondria are numerous and particularly elongated (arrow). Lipid droplets are present and often clustered in twos or threes and associated with glycogen rosettes. TEM, original magnification $\times 12,000$.
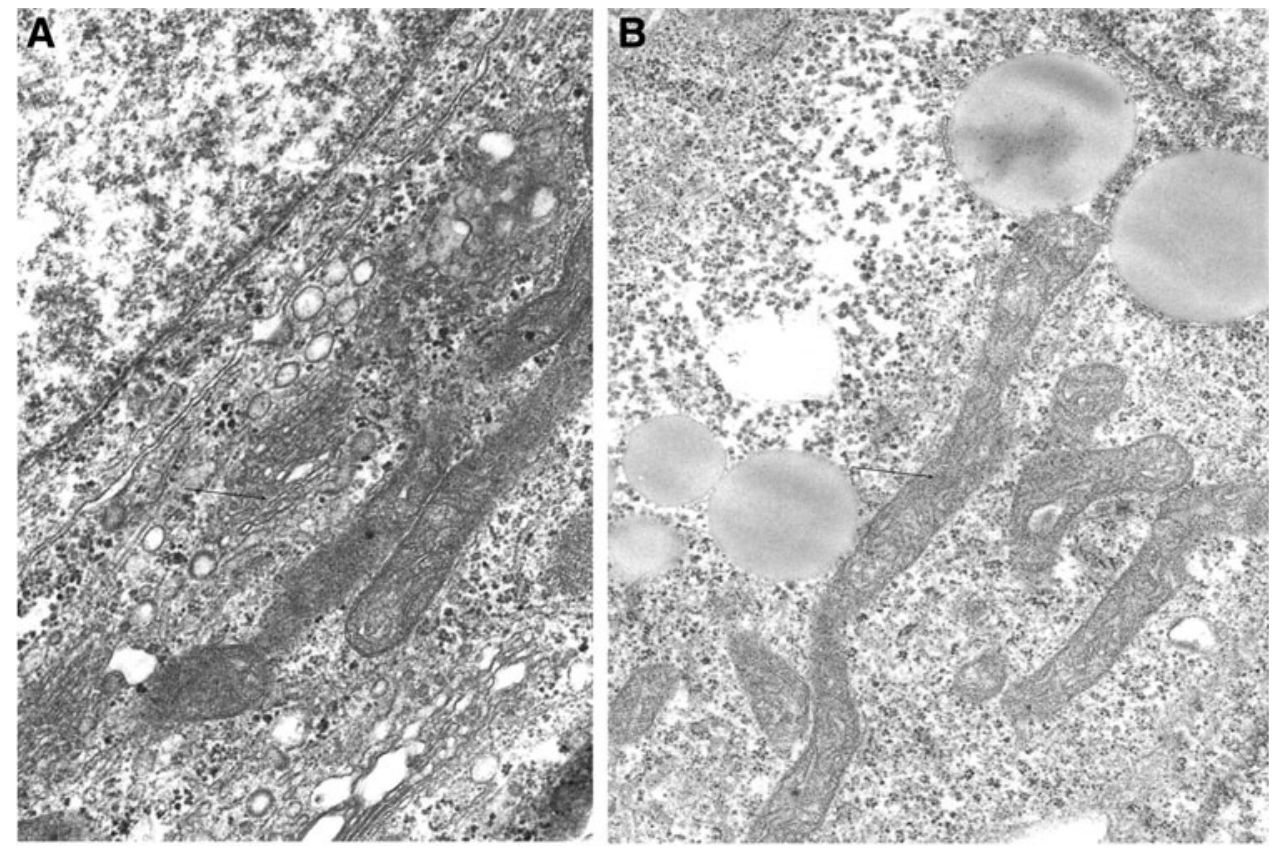


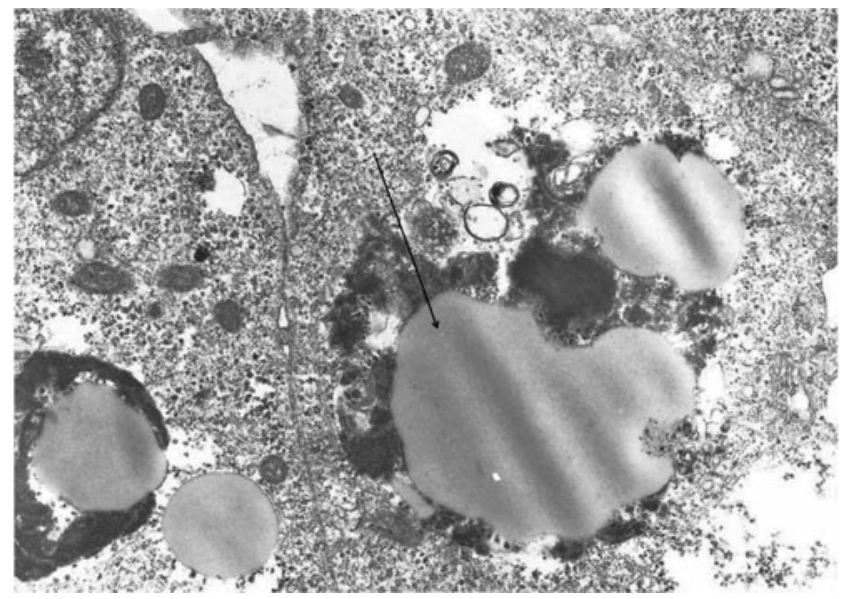

FIG. 6. Presence of autophagosomes in H9 hIPSCs cultured on MEFs. These two cells have voluminous autophagic vacuoles in their cytoplasm (arrow). These vacuoles contain fused lipid droplets enclosed in a contrasting dense material. TEM, original magnification $\times 10,000$.

MEFs without hESCs or hIPSCs. We confirmed the murine origin of these viral particles, since we showed their presence in MEFs, budding at the level of the plasma membrane. We never observed these particles at the cellular level of hESCs or hIPSCs.

H9 hESCs were analyzed in the same culture conditions as H9 hIPSCs. The general aspect of H9 hESCs was found to be similar to that of H9 hIPSCs; however, the organelle density inside the cells appeared to be lower.

Each H9 hESC colony formed a discoid structure. Cells were characterized by a high nucleo-cytoplasmic ratio, a variable number of nucleoli, and apical differentiations of epithelial type in the cells in contact with the medium (Fig. 7A). Ducts were also present inside the colony (Fig. 7B). The cytoplasm contained ribosomes and elongated mitochondria (Fig.
7C) as well as glycogen associated with lipid droplets. The Golgi apparatus appeared less present, while the sarcoplasmic reticulum was scarce. The nucleus was euchromatic and present reticulated nucleoli (Figure 7D).

\section{Structural features of hIPSCs and hESCs cultured in presence of Matrigel}

The cells that we observed in the Matrigel culture contained several distinct features from hIPSCs and hESCs, the most prominent being the presence of cells with mesenchymal morphology (Fig. 8A-8C). These cells exhibited a fusiform morphology. They were loosely attached to each other by thin expansions for which specialized junctions were identified (Fig. 8D). At the upper membrane, we observed microvilli and a thick densification under the membrane resembling classical actin seen in epithelial cells (Fig. 8D).

The second cell type corresponded to cells having lost the mesenchymal morphology and connected with specialized junctions (Figs. 8A, 8B, 9A, and 9C). These cells were accompanied by cells with typical epithelial morphology organized most often in one or two layers (Figs. 8A and 9A) and rarely in multilayers (Fig. 9B). These cells were connected by junctions at their upper lateral side (Figs. 9D and 10E).

Characteristics of non-differentiation were similar in hIPSCs and hESCs cultured on Matrigel and in hIPSCs and hESCs cultured on MEFs (Figs. 9D, 10A, 10D, and 10E).

Moreover, a large amount of droplets containing either lipids or glycogen were observed in the cytoplasm (Figs. 10A10C). In contrast, autophagic vacuoles were rarely observed, and mitochondria appeared shorter in size in cells cultured in the presence of Matrigel.

\section{Structural analysis of partially reprogrammed hIPSCs}

Partially reprogrammed cells were defined as clones with no extinction of pluripotency transgenes. ${ }^{25}$ By optical microscopy,
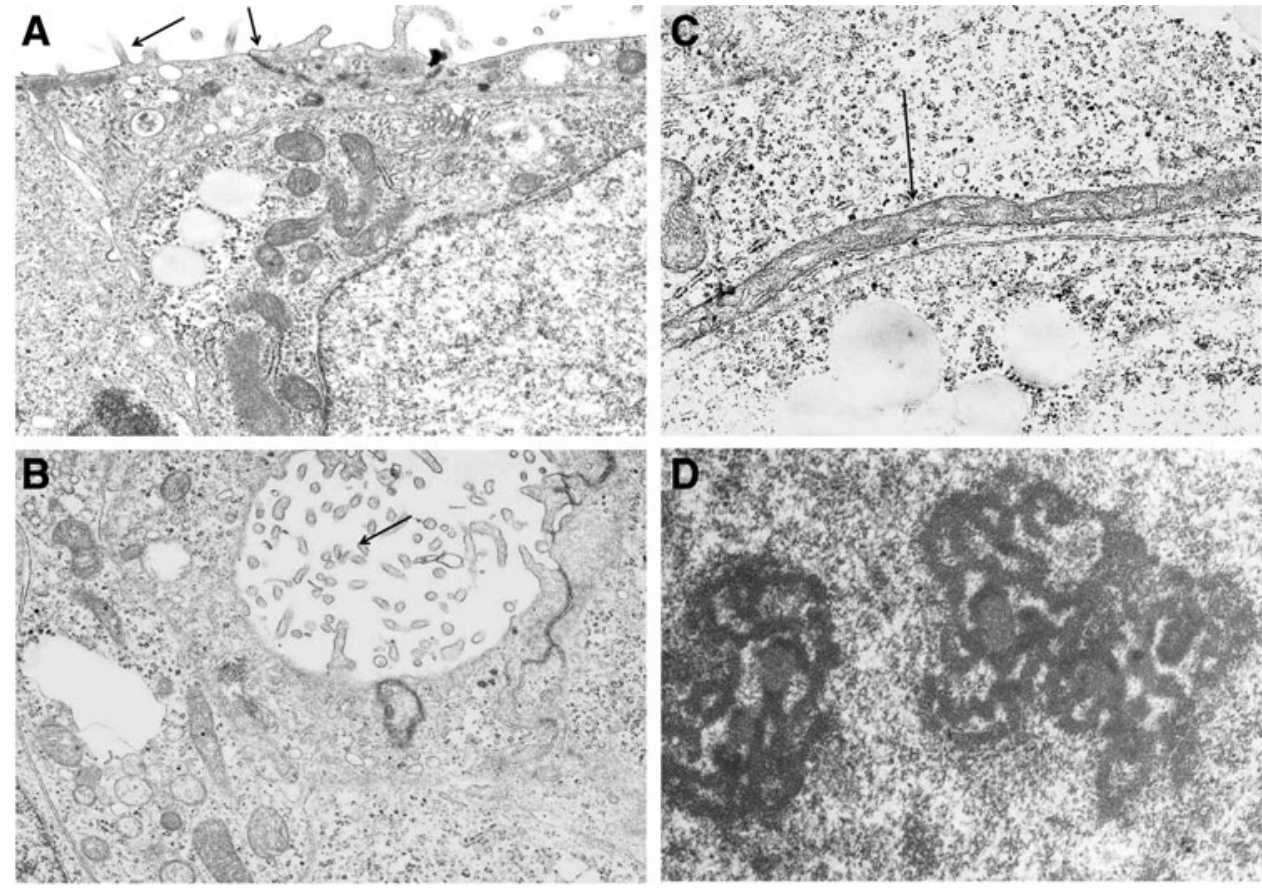

FIG. 7. Ultrastructural analysis of H9 hESCs cultured on MEF. (A) Apical differentiations of epithelial type (arrow) were seen in the cells in contact with the medium. The nucleus is euchromatic. TEM, original magnification $\times 10,000$. (B) Inner ducts (arrow) are also present inside the colony. TEM, original magnification $\times 10,000$. (C) The cytoplasm contains ribosomes, and glycogen is associated with lipid droplets. Mitochondria are elongated (arrow). TEM, original magnification $\times 15,000$. (D) The nucleoli are reticulated. TEM, original magnification $\times 15,000$. 

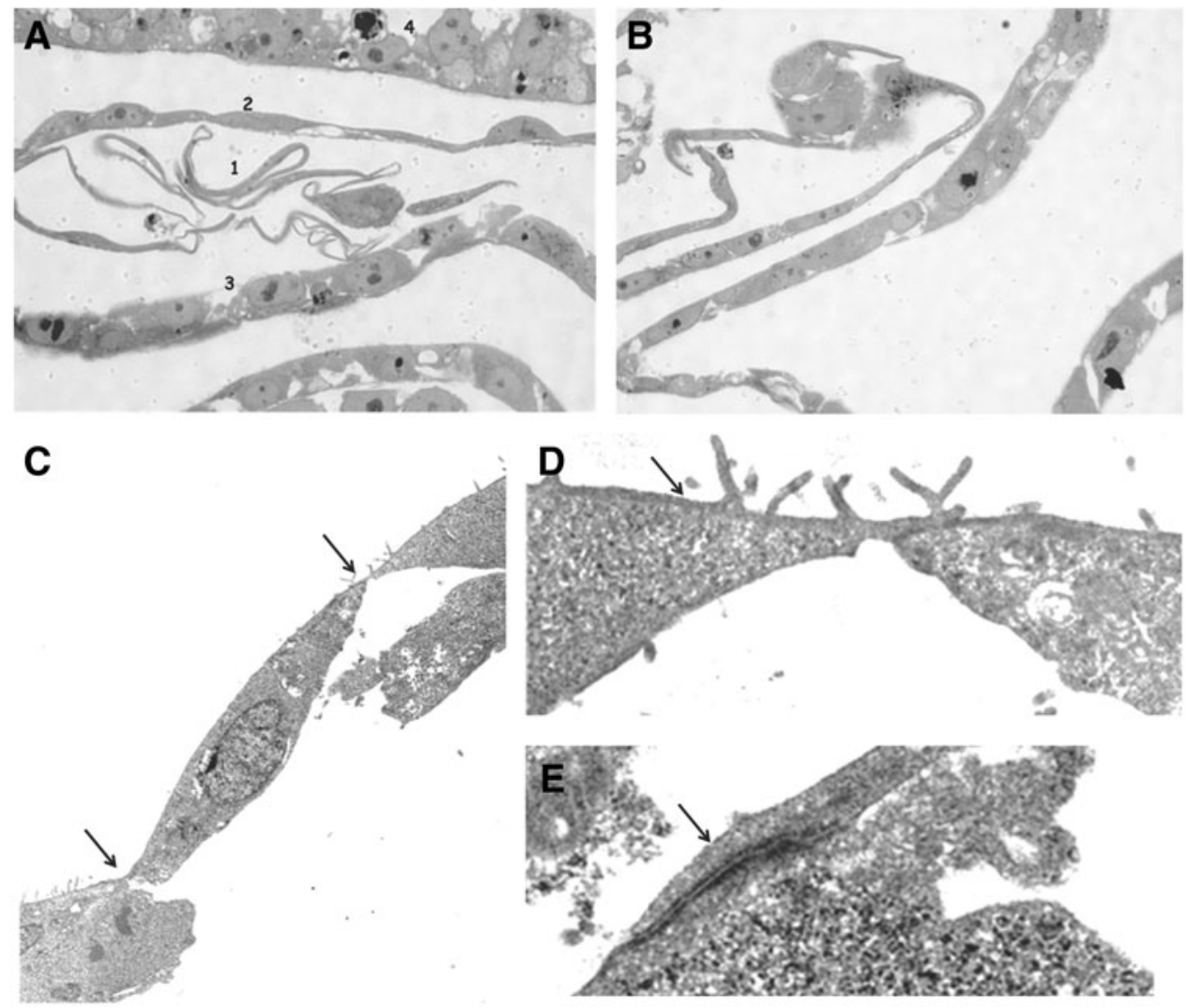

FIG. 8. Structural analysis of H9 hIPSCs cultured on Matrigel. (A) Semi-thin sections of H9 hIPSCs. This panel illustrates the different aspects of the cells and colonies (1, 2, 3, 4). Cells are organized in one layer of flattened cells (1). Cells are larger and have a mesenchymal morphology (2). Cells begin to have an epithelial morphology (3). Cells are organized in colony of two or three layers (4). Optical microscopy, original magnification $\times 400$. (B) Semi-thin sections of H9 hIPSCs. Transition from mesenchymal to epithelial morphology is observed in the same layer of cells. Optical microscopy, original magnification $\times 400$. $(\mathbf{C})$ The cells are loosely attached to each other by thin expansions (arrow). TEM, original magnification $\times 2500$. (D) The cells, which are loosely attached, present a thick densification under the membrane (arrow) and microvilli. TEM, original magnification $\times 15,000$. (E) The cells are connected by specialized junctions (arrow). TEM, original magnification $\times 15,000$.

these cells exhibit a round-shape aspect (Fig. 11A). Interestingly at ultrastructural level, few heterochromatin coexisted with euchromatin in some cells (Fig. 11B), whereas in others, the nucleus was found to be euchromatic and the nucleolus was dense without reticulated structure. In the cytoplasm, morphologically abnormal mitochondria often gathered with granular reticulum. Few lipid droplets were present, and abnormal structures were observed in almost all cells observed (Fig. 11C).

The global architecture of pluripotent stem cells and mesenchymal stem cells observed by light microscope and by electron microscope is schematically illustrated in Fig. 12.

\section{Discussion}

Using a reversible differentiation methodology, this study aimed to determine the ultrastructural characteristics of hIPSCs derived from hMSCs, which were initially obtained from hESCs. Using this strategy, we were able to analyze the ultrastructural characteristics of pluripotent cells as compared to their differentiated state in the same cellular background. hIPSCs generated from hESCs were grown either in MEF layers or without stromal support in Matrigel. In both culture conditions, hIPSCs exhibited patterns of epithelial cells.

\section{Visualization of a mesenchymal-to-epithelial transition}

We have shown with this reversible programming strategy that the reversion from the differentiated (MSC) to pluripotent (IPSC) state is accompanied by the morphological features of a mesenchymal-to-epithelial transition (MET). When IPSCs were cultured on Matrigel, we could easily identify three different steps leading to epithelial formation. We found that cells with mesenchymal morphology gathered by the way of thin and long expansions having actin under the upper plasmic membrane. Cells with microvilli at their upper side began to be joined with specialized junctions. Finally colonies were generated with one or two layers of cells with typical aspects of epithelial cells characterized by their polarity and their junctional system. These IPSCs have an epithelial morphology, present actin under the upper cytoplasmic membrane, and possess specialized junctions corresponding to the morphological demonstration of E cadherin presence. This corresponds to the ultrastructural manifestations of a typical MET according to reported criteria. ${ }^{10}$ Indeed induced pluripotency has been shown to start with an initiation phase characterized by the loss of mesenchymateous markers such as Snail and the appearance of epithelial markers as E cadherin, a cell-adhesion 

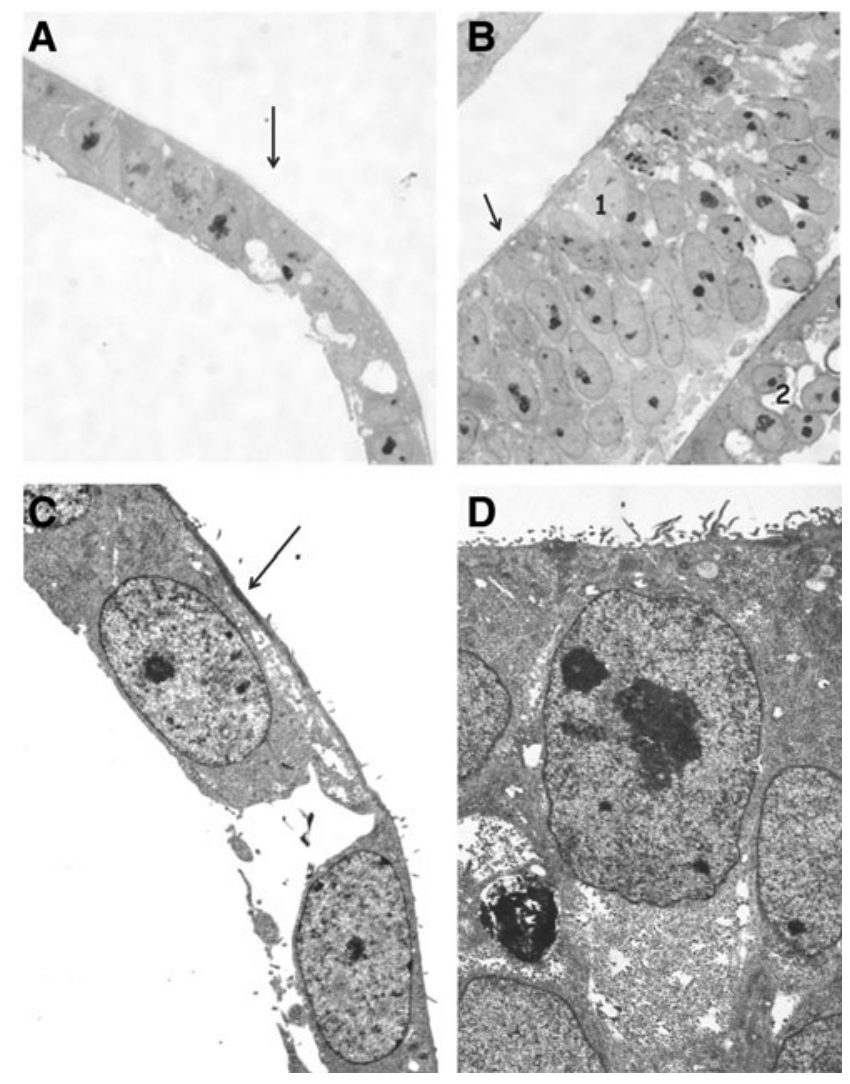

FIG. 9. Epithelial aspect of H9 hIPSCs cultured on Matrigel. (A) Semi-thin section of H9 hIPSCs. The layer is formed of polarized epithelial cells with microvilli at the apical side (arrow). Optical microscopy, original magnification $\times 400$. (B) Semi-thin section of H9 hIPSCs. The colony (1) is formed of three to four layers of cells with microvilli at the apical side (arrow). The colony (2) is formed of two layers. Large vacuoles are seen inside the cells. There are one or two nucleoli per cell. Optical microscopy, original magnification $\times 400$. (C) Cells have an intermediate morphology. They presented thick densifications under the membrane (arrow) and microvilli at the apical side. TEM, original magnification $\times 3000$. (D) The cells of the layer are of epithelial type. TEM, original magnification $\times 10,000$.

molecule crucial for ESC pluripotency. ${ }^{11}$ It has also been shown that during the programming process, the actin is localized in cortical zones. These modifications are regulated by bone morphogenetic protein (BMP) and miRNA. ${ }^{12}$ More recently, the importance of epigenetic modifications in somatic cell reprogramming began to be identified. ${ }^{13}$

The epithelial formation obtained with Matrigel or MEF in our experiments are in agreement with the notion that MET is an "required step" for fibroblasts reprogramming into IPSCs. ${ }^{10}$

\section{Specific ultrastructure of hIPSCs cultured on MEFs}

We described particular characteristics and morphological organization of hIPSCs cultured in presence of MEFs. We first found that hIPSCs gather, apart from the MEFs, creating multilayer colonies with a cohesive structure. The structure of these IPSC colonies resembled the architecture of inner mass cells at the human blastocyst stage of development, human ESCs, and mouse embryoid bodies ${ }^{7,8,14-16}$ and were in concordance with the results of Totonchi et al. ${ }^{6}$ on hIPSCs. We found secondly that colonies are in contact with the culture environment by the microvillar side of the epithelial cells and inside the colonies by large intercellular spaces and internal ducts, allowing transport from the culture medium to the cells deeper in the colony. Such structures had been reported in mouse embryoid bodies after 5 days of culture. ${ }^{16}$ Although there are no data for the functional role of these ducts, we can speculate that they could provide signaling or nutrient elements as demonstrated by the presence of numerous particles in their lumen.

\section{Identification of viral particles}

Viral elements of different sizes were found to be present in the supernatant of the culture medium of IPSC, when they were cultured on MEF. As previously reported, the mitomycin-treated MEFs used as feeder cells can bear viral particles similar to C-type retrovirus of the MuLV group. ${ }^{17,18}$ Thus, this viral environment is avoided when IPSCs are cultured in presence of Matrigel. However, in our experimental conditions using Matrigel or MEFs, neither hIPSCs nor hESCs observed were infected.

\section{Characteristics of undifferentiated cells observed in the presence or absence of MEFs}

The nucleo-cytoplasmic ratio of the cells was found to be higher than that of hMSCs. Such high ratio has also been reported in the postfertilization cleavage cell cycle, ${ }^{19}$ in $\mathrm{hESCs}$, and in hIPSCs obtained from human dermal fibroblasts. ${ }^{6,20}$ Our analyses revealed characteristics of undifferentiated cells at the level of hIPSC nucleus such as the presence of euchromatin and the voluminous reticulated nucleoli.

A striking aspect of the nucleus of hIPSCs compared to the hMSCs was the presence of open chromatin (euchromatin), which is one of the hallmarks of stem cells. ${ }^{21,22}$ Similarly, Fussner et al. ${ }^{23}$ reported the unusually dispersed $(10 \mathrm{~nm})$ heterochromatin fibers in bona fide IPSCs and in pluripotent embryonic stem cells by using correlative electron spectroscopic imaging.

hIPSCs were also found to contain essentially a single nucleolus per cell and rarely several nucleoli. Both the presence of euchromatin by itself and the voluminous reticulated nucleolus structure open to the nucleoplasm reflected an intense activity in hIPSC nuclei as reported in hESCs. ${ }^{8}$ These results obtained at the ultrastructural level can be linked with those of Efroni et al., ${ }^{24}$ who showed by using whole genome mouse gene arrays that the ESC genome is transcriptionally globally hyperactive in both coding and noncoding regions. Indeed, normally silent repeat regions are active, and tissue specific genes are sporadically expressed at a low level. As a consequence, a large amount of ribosomes were found to be present in the cytoplasm, however, without a specific synthesis activity because neither Golgi nor reticula are developed as much as in hMSCs. Mitochondria were found to be highly elongated in IPSCs cultured in the presence of MEFs as described in inner cell mass cells and hESCs. ${ }^{7}$

Lipid droplets associated with glycogen were present in the majority of IPSCs. This association had been reported in a variety of undifferentiated cells in different evolutionary 
FIG. 10. Ultrastructural analysis of H9 hIPSCs cultured on Matrigel. (A) The epithelial cells contain lipid droplets associated with glycogen. TEM, original magnification $\times 15,000$. (B) The droplets (arrow) are filled with an unidentified material. TEM, original magnification $\times 10,000$. (C) The nucleus of the cell contains euchromatic and two nucleoli. The cytoplasm does not present cellular organelles but is filled with material gathered in droplets. TEM, original magnifica-

tion $\times 10,000$. (D) In the nucleus, the chromatin is of euchromatin type. The nucleolus has a well-defined reticulated structure. TEM, original magnifica-

tion $\times 10,000$. $(\mathbf{E})$ The cells are closely related according to the presence of specialized junctions (arrow). The cytoplasm contains glycogen and lipid droplets and mitochondria. Some Golgi complexes are present close to the nucleus (arrow). TEM, original magnification $\times 10,000$.

phyla and as reported by Park et al. ${ }^{8}$ in hESCs. Moreover, this observation is in agreement with our previous study using infrared microspectroscopy highlighting a close association between lipid and glycogen storage in hIPSCs and $\mathrm{hESCs}$ and the fully pluripotency status. ${ }^{25}$
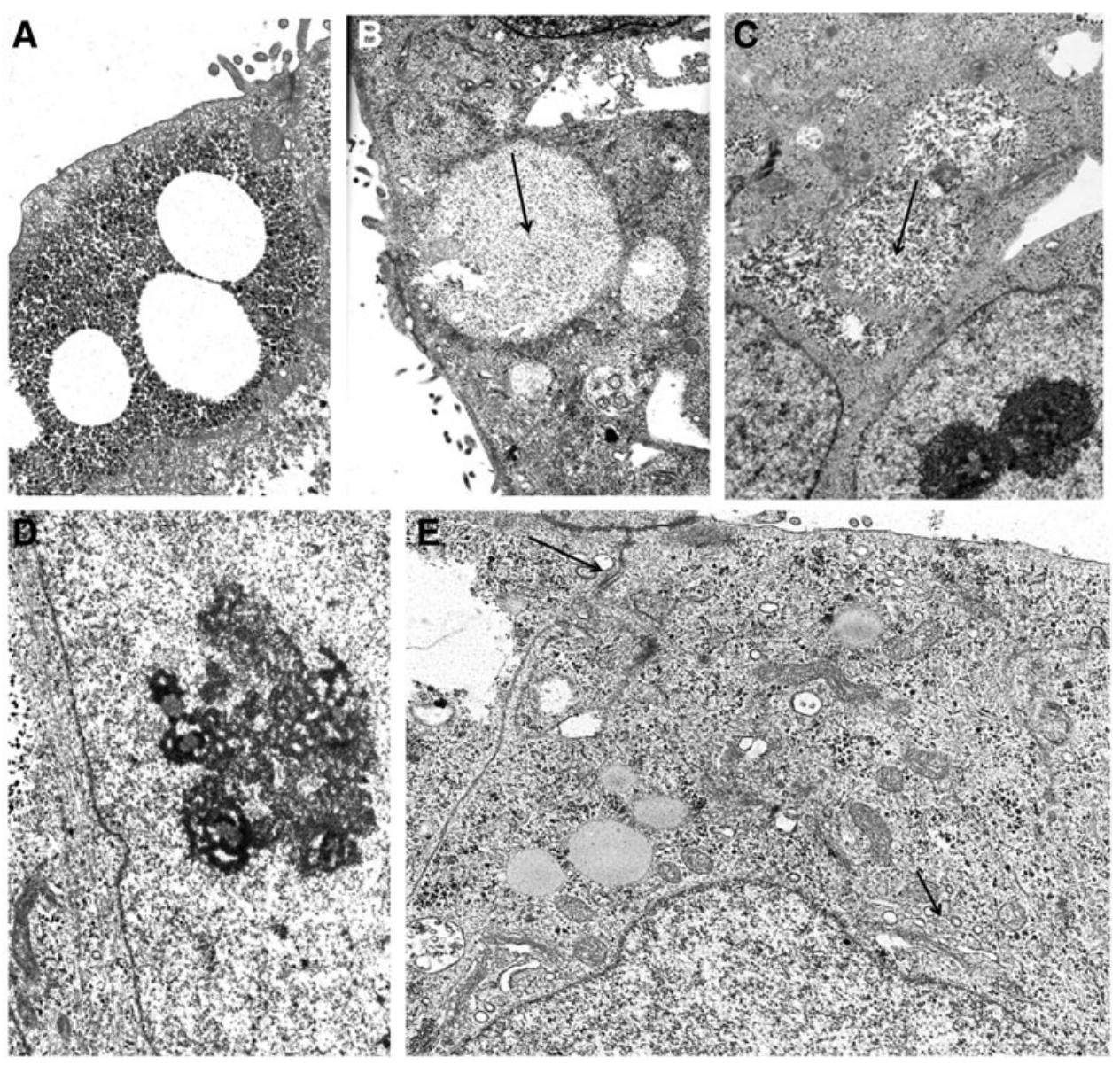

We have also identified morphological characteristics specific to culture type. The macrophagosomes were particularly prominent in hIPSCs cultured in the presence of MEFs as compared to hMSCs, and they mainly contained several lipid droplets and glycogen rosettes. The presence of these macrophagosomes
FIG. 11. Partially reprogrammed IPSCs cultured on Matrigel. (A) Semi-thin section of partially reprogrammed IPSCs cultivated in the presence of Matrigel. The cells are round and isolated. Optical microscopy, original magnification $\times 400$. (B) The nucleus presents heterochromatin (arrow). In the cytoplasm atypical mitochondria are often associated with rough endoplasmic reticulum (arrow). TEM, original magnification $\times 10,000$. (C) Atypical mitochondria are gathered in a portion of cytoplasm (arrow). The nucleoplasm is of euchromatic type and the nucleolus is dense. TEM, original magnification $\times 10,000$.

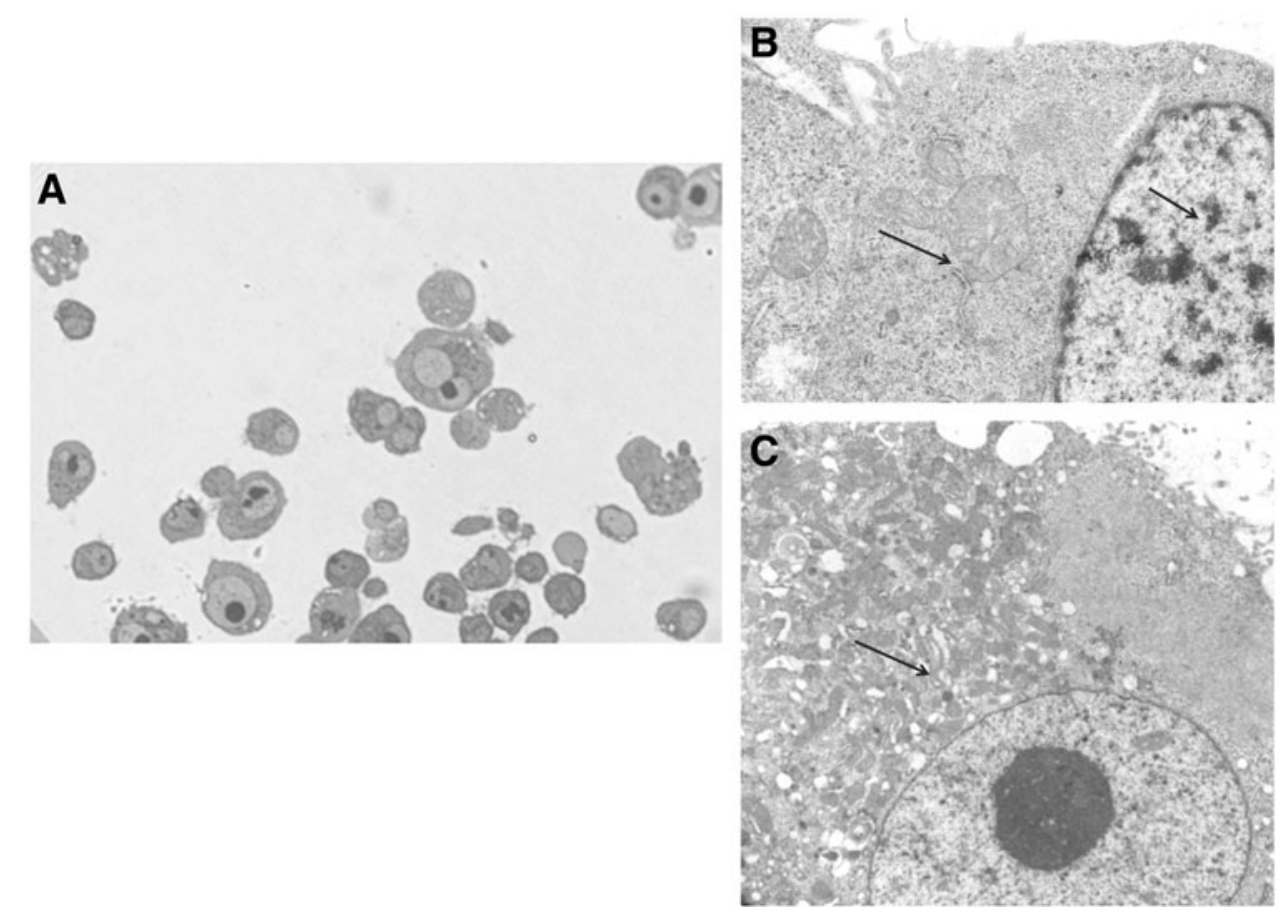




\section{CELL ARCHITECTURE OF HUMAN H9 IPSC WITH NATIVE MS CELLS}

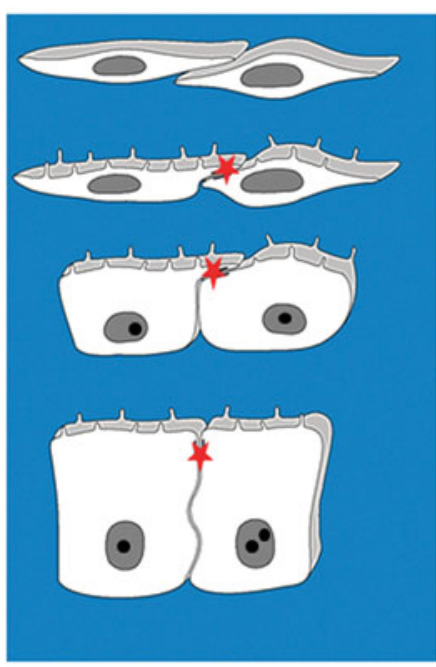

H9 hIPSC cultivated with Matrigel

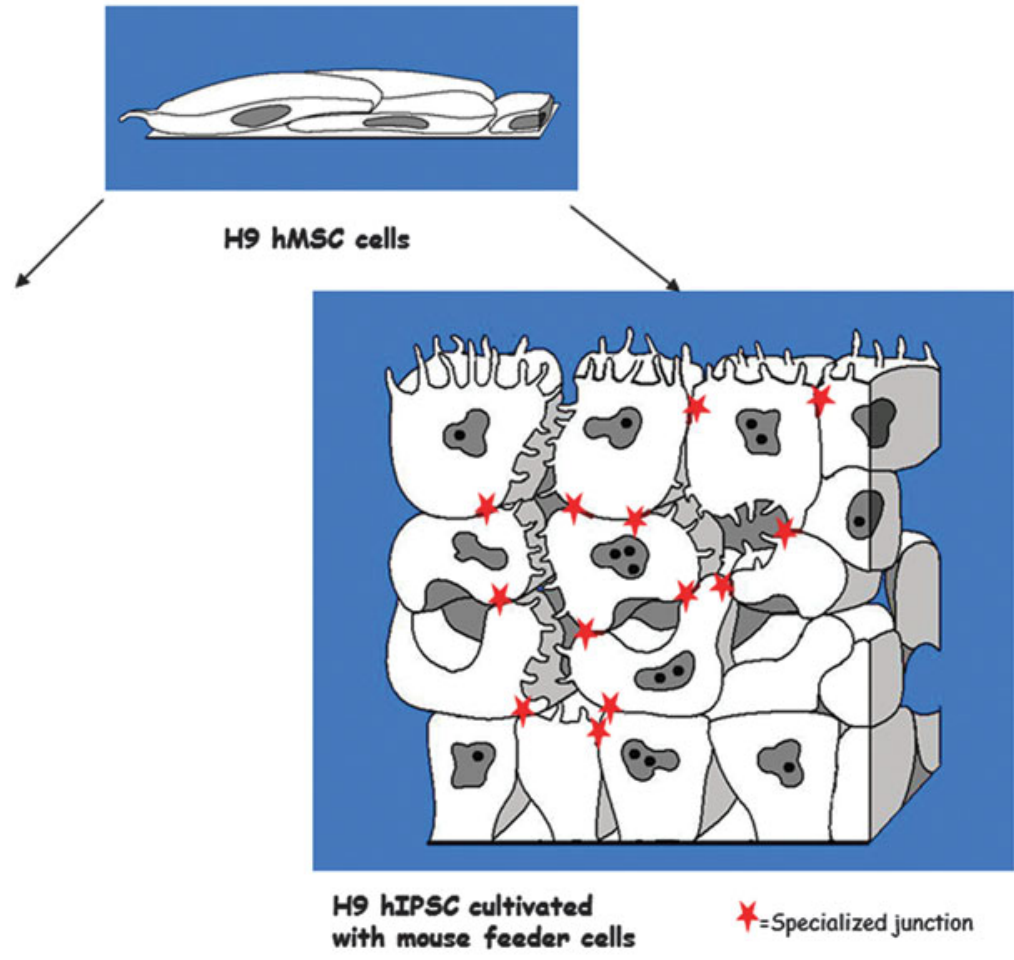

FIG. 12. Schematic representation of the different stages of mesenchymal-to-epithelial transition and of the architecture of hIPSC colonies, according to the structural observations reported in this study.

could be due the architecture of the colony, with several cell layers undergoing autophagy due to the lack of nutrients, as demonstrated by Lock and Debnath. $^{26}$

In contrast, IPSCs cultured on Matrigel were organized as colonies with one or two layers with few numbers of macrophagosomes. They were also found to contain a large amount of more or less empty vesicles that could correspond to lipid or glycogen in intermediate stages.

\section{Morphological features of partially programmed cells}

Our observations reflect that the experimental process leading to IPSCs from MSCs is a dynamic process written at the subcellular level that can be divided in different steps. The incomplete MET observed in some cells in Matrigel culture conditions, and the absence of MET observed in the partially reprogrammed IPSCs (F50 line) suggest that ultrastructural analysis can reveal at the morphological level (complete versus incomplete MET) partial reprogramming that can be correlated with other characteristics of this state.

In conclusion, electron microscopic analysis revealed specific ultrastructural aspects of reprogrammed pluripotent cells, depending on intrinsic and extrinsic conditions. These observations highlight the valuable use of electron microscopy to better define the pluripotency at the single-cell level and as a prospective arsenal of criteria to define the safety of virus-free clinical grade IPSCs.

\section{Acknowledgments}

We thank G. Pierron, $\mathrm{PhD}$, and the members of his team for valuable information on viral structure, M. Mitjavila, PhD, for kindly providing mouse embryo fibroblasts, J. LoiselDuwattez and O. Morassi (technical personnel) for excellent technical assistance, and D. Schoevaert, PhD, for skillful drawing. Grants were provided by INSERM, University Paris Sud, and ANR (Agence Nationale de la Recherche) Investissements Avenir, INGESTEM Infrastructure.

\section{Author Disclosure Statement}

No competing financial interests exist.

\section{References}

1. Stadtfeld M, Hochedlinger K. Induced pluripotency: history, mechanisms, and applications. Genes Dev. 2010;24:22392263.

2. Takahashi K, Yamanaka S. Induction of pluripotent stem cells from mouse embryonic and adult fibroblast cultures by defined factors. Cell. 2006;126:663-676.

3. Yu J, Vodyanik MA, Smuga-Otto K, et al. Induced pluripotent stem cell lines derived from human somatic cells. Science. 2007;318:1917-1920.

4. Coulombel L. Pluripotency: defining standards. Med Sci (Paris). 2009;25:798-801.

5. Zeuschner D, Mildner K, Zaehres H, et al. Induced pluripotent stem cells at nanoscale. Stem Cells Dev. 2010;19:615-620.

6. Totonchi M, Taei A, Seifinejad A, et al. Feeder- and serumfree establishment and expansion of human induced pluripotent stem cells. Int J Dev Biol. 2010;54:877-886.

7. Sathananthan H, Pera M, Trounson A. The fine structure of human embryonic stem cells. Reprod Biomed Online. 2002;4:56-61. 
8. Park SH, Park SH, Kook MC, et al. Ultrastructure of human embryonic stem cells and spontaneous and retinoic acid-induced differentiating cells. Ultrastruct Pathol. 2004;28:229-238.

9. Giuliani M, Oudrhiri N, Noman ZM, et al. Human mesenchymal stem cells derived from induced pluripotent stem cells downregulate NK cell cytolytic machinery. Blood. 2011;118:3254-62.

10. David L. Mesenchymal-to-epithelial transition: a necessary initial step towards reprogrammation of fibroblasts. Med Sci (Paris). 2010;12:1030-1032.

11. Redmer T, Diecke S, Grigoryan T, et al. E-cadherin is crucial for embryonic stem cell pluripotency and can replace OCT4 during somatic cell reprogramming. EMBO Rep. 2011;12:720-726.

12. Samavarchi-Tehrani P, Golipour A, David L. Functional genomics reveals a BMP-driven mesenchymal-to-epithelial transition in the initiation of somatic cell reprogramming. Cell Stem Cell. 2010;7:64-77.

13. Hu X, Zhang L, Mao SQ, et al. Tet and TDG mediate DNA Demethylation essential for mesenchymal-to-epithelial transition in somatic cell reprogramming. Cell Stem Cell. 2014; $14: 1-11$.

14. Nikas G. Cell-surface morphological events relevant to human implantation. Hum Reprod. 1999;14:37-44.

15. Mumaw JL, Machacek D, Shelds JP, et al. Neural differentiation of human embryonic stem cells at the ultrastructural level. Microsc Microanal. 2010;16:80-90.

16. Mogi A, Ichikawa H, Matsumoto $\mathrm{C}$, et al. The method of mouse embryoid body establishment affects structure and developmental gene expression. Tissue Cell. 2009;41: 79-84.

17. Amit M, Winkler ME, Menke S, et al. No evidence for infection of human embryonic stem cells by feeder cellderived murine leukemia viruses. Stem Cells. 2005;23: 761-771.

18. Cobo F, Navarro JM, Herrera MI, et al. Electron microscopy reveals the presence of viruses in mouse embryonic fibroblasts but neither in human embryonic fibroblasts nor in human mesenchymal cells used for hESC maintenance: toward an implementation of microbiological quality assurance program in stem cell banks. Cloning Stem Cells. 2008; 10:65-74.

19. Aiken CE, Swoboda PP, Skepper JN, et al. The direct measurement of embryogenic volume and nucleo-cytoplasmic ratio during mouse pre-implantation development. Reproduction. 2004;128:527-535.

20. Wakao S, Kitada M, Kuroda Y, et al. Morphologic and gene expression criteria for identifying human induced pluripotent stem cells. PLoS One. 2012;7(12):e48677.

21. Ahmed K, Dehghani H, Rugg-Gunn P, et al. Global chromatin architecture reflects pluripotency and lineage commitment in the early mouse embryo. PLoS One. 2010;5(5):e10531.
22. Gaspar-Maia A, Alajem A, Polesso F, et al. Chd1 regulates open chromatin and pluripotency of embryonic stem cells. Nature. 2009;460:863-868.

23. Fussner E, Djuric U, Strauss M, et al. Constitutive heterochromatin reorganization during somatic cell reprogramming. EMBO J. 2011;30:1778-1789.

24. Efroni S, Duttagupta R, Cheng J, et al. Global transcription in pluripotent embryonic stem cells. Cell Stem Cell. 2008;2:437-47.

25. Sandt C, Féraud O, Oudrhiri N, et al. Identification of spectral modifications occurring during reprogramming of somatic cells. PLoS One. 2012;7(4):e30743.

26. Lock R, Debnath J. Extracellular matrix regulation of autophagy. Curr Opin Cell Biol. 2008;20:583-588.

Address correspondence to: Dr. Annelise Bennaceur-Griscelli Inserm U935, ES-TEAM Paris Sud, Infrastructure INGESTEM Institut André Lwoff, Campus CNRS 7 rue Guy Moquet 94802 Villejuif

France

E-mail: annelise.bennaceur@pbr.aphp.fr

Dr. Anne-Marie Courtot Inserm U935 Institut André Lwoff, Campus CNRS 7 rue Guy Moquet 94802 Villejuif France

E-mail: mariecourtot@hotmail.fr

$\begin{aligned} & \text { Abbreviations Used } \\ \mathrm{bFGF} & =\text { basic fibroblast growth factor } \\ \mathrm{DMEM} & =\text { Dulbecco's modified Eagle's medium } \\ \mathrm{ESC} & =\text { embryonic stem cell } \\ \mathrm{hESC} & =\text { human embryonic stem cell } \\ \mathrm{hIPSC} & =\text { human induced pluripotent stem cell } \\ \mathrm{hMSC} & =\text { human mesenchymal stem cell } \\ \mathrm{IPSC} & =\text { induced pluripotent stem cell } \\ \mathrm{MEF} & =\text { murine embryonic fibroblast } \\ \mathrm{MET} & =\text { mesenchymal-to-epithelial transition } \\ \mathrm{MSC} & =\text { mesenchymal stem cell } \\ \mathrm{MuLV} & =\text { murine leukemia virus } \\ \mathrm{PBS} & =\text { phosphate-buffered saline } \\ \mathrm{TEM} & =\text { transmission electron microscopy }\end{aligned}$

